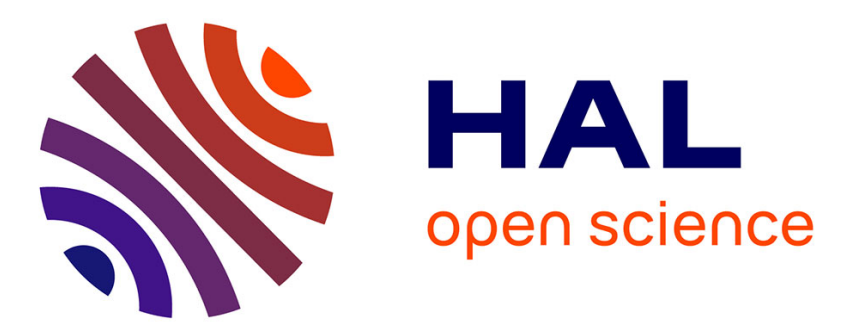

\title{
CURRENT DISTRIBUTION OF AC SURFACE DISCHARGES AND ASSOCIATED CHEMISTRY
}

Emmanuel Odic, Alice Goldman, Max Goldman, Marielle Dhainaut, Rémi

Dussart

\section{- To cite this version:}

Emmanuel Odic, Alice Goldman, Max Goldman, Marielle Dhainaut, Rémi Dussart. CURRENT DISTRIBUTION OF AC SURFACE DISCHARGES AND ASSOCIATED CHEMISTRY. Journal of Electrostatics, 2006, 64 (7-9), pp.477-484. hal-00221383

\section{HAL Id: hal-00221383 \\ https://hal-centralesupelec.archives-ouvertes.fr/hal-00221383}

Submitted on 28 Jan 2008

HAL is a multi-disciplinary open access archive for the deposit and dissemination of scientific research documents, whether they are published or not. The documents may come from teaching and research institutions in France or abroad, or from public or private research centers.
L'archive ouverte pluridisciplinaire HAL, est destinée au dépôt et à la diffusion de documents scientifiques de niveau recherche, publiés ou non, émanant des établissements d'enseignement et de recherche français ou étrangers, des laboratoires publics ou privés. 


\title{
CURRENT DISTRIBUTION OF AC SURFACE DISCHARGES AND ASSOCIATED CHEMISTRY
}

\author{
E. Odic ${ }^{\S}$, A. Goldman ${ }^{*}$, M. Goldman ${ }^{*}$, M. Dhainaut ${ }^{*}$ and R. Dussart*1 \\ ${ }^{\S}$ Département Energie, SUPELEC, \\ F-91192 Gif-sur-Yvette Cedex, France \\ Corresponding author E-mail: emmanuel.odic@supelec.fr \\ Tel. : $\quad 33(0) 1.69 .85 .15 .26$ \\ Fax : $\quad 33(0) 1.69 .85 .12 .34$ \\ ${ }^{*}$ Laboratoire de Physique des Gaz et des Plasmas (Université Paris Sud - CNRS) \\ Equipe Décharges Electriques et Environnement, SUPELEC, \\ F-91192 Gif-sur-Yvette Cedex, France
}

\begin{abstract}
It is shown that ac discharges propagating at an air / dielectric interface, though of planar structure, behave, till a critical voltage $\mathrm{V}_{\text {crit }}$, as corona discharges in an air gap, with similar propagation fields for the filamentary discharge components and similar glow components. This leads to consider the surface discharges as gas discharges propagating above the dielectric surface. Beyond $\mathrm{V}_{\text {crit, }}$, the retention of charges by the dielectric surface becomes ineffective, due to the gas heating in the filamentary channels and to the heat subsequently transferred from these channels to the surface. In return, the surface gives its energy excess back to the discharge, so opening the way, on the surface, to leader-like discharges of higher conductivity, needing about 10 times lower fields to propagate.
\end{abstract}

Key words: surface discharge, gas/surface interface, discharge propagation, surface modification.

\section{INTRODUCTIVE BACKGROUND}

Lichtenberg was the first in 1778 [1] to report observations on surface discharges. His approach consisted in sprinkling a mixture of two powders on dielectric surfaces after exposure to the discharge: red lead oxide positively charged (thus attracted by the negative charges of the surface), and yellow sulphur powder negatively charged (attracted by the residual positive charges). So were obtained coloured figures visualizing not only the expansion limits of the discharge on the surface, but also the distribution of the charges of each polarity remaining on it.

\footnotetext{
${ }^{1}$ Present address : Groupe de Recherche sur l’Energétique des Milieux Ionisés (Université d’Orléans CNRS)
} 
More than one hundred years after, Toepler [2,3] also realized observations on discharges developing on a dielectric plate, inserted between the two electrodes of a point-to-plane electrode system. He succeeded with the statement of two empirical rules, still in use under the denomination of first and second Toepler laws:

- the first law stipulates that, for dc pulsed potentials $V<V_{c r i t}$, the discharges expand over a circular area looking homogeneous to the naked eye; a particular feature of this area is that its radius $r_{d}$ increases proportionally with the voltage, with coefficients of proportionality $E=V / r_{d}$ differing with the polarity of the applied voltage, but not with the characteristics of the dielectric plate: $E=5.5 \mathrm{kV} / \mathrm{cm}$ in ambient air with positive pulsed voltages applied at the point electrode, $E=11.5 \mathrm{kV} / \mathrm{cm}$ with negative pulsed voltages applied at the point electrode.

- the second law defines the critical voltage $V_{c r i t}$ for which filamentary discharges are seen to develop from the border of the first law circular area and shows that this transition voltage is clearly depending on the dielectric plate characteristics while only little on the discharge polarity:

$V_{\text {crit }}=110\left(e / \varepsilon_{r}\right)^{1 / 2}$ in positive polarity, with $V_{\text {crit }}$ in $\mathrm{kV}$, $e$ the dielectric plate thickness in cm and $\varepsilon_{r}$ its relative permittivity $V_{\text {crit }}=119\left(e / \varepsilon_{r}\right)^{1 / 2}$ in negative polarity.

A significant break through has been achieved by Murooka et al. [4,5] in the understanding of the first Toepler law discharges phenomena. He introduced the idea that the circular luminous area formed by these discharges is actually formed by a great number of filamentary discharges evenly distributed around the point of contact of an electrode tip with the dielectric surface.

Our aim is to extend this basic knowledge further, far enough to be able to enter into the physical mechanisms into play. The filamentary discharges evidenced by Murooka et al. stimulated the search for similarities, reported in this paper, between conventional gas discharges (e.g. corona discharges) and surface discharges. General laws depicting the discharge behaviour of gas discharges will be tested with surface discharges. Correlations between the discharge propagation on an insulating surface and the pulsed 
discharge current will be proposed, whereas the diffuse discharge component will be investigated through its chemical properties. For this purpose, two different experimental set-ups will be used,

(i) one aimed to study the propagation of filamentary discharges on an dielectric surface,

(ii) the other one more specifically designed to study the transport of the gaseous products from a diffuse surface discharge along an insulating surface, in correlation with the hydrodynamic properties of the discharge.

\section{EXPERIMENTAL}

\section{System I (Fig. 1)}

The study of the discharges propagation is performed with a first electrode arrangement consisting of two electrodes, placed on both sides of a dielectric plate, as in systems commonly used for dielectric barrier discharges. The tip of a point electrode (stainless steel, $1 \mathrm{~mm}$ diameter, $50 \mu \mathrm{m}$ tip radius) is in contact with the insulating surface. This electrode is polarized with an ac $16.7 \mathrm{kHz}$ high voltage (measured using a high voltage probe 1/1000 ratio). On the opposite side of the dielectric plate, a metallic disk is connected to ground through a $50 \Omega$ resistor $\mathrm{R}$ used for discharge current measurements. The dielectric plate is a $\mathrm{Al}_{2} \mathrm{O}_{3} / \mathrm{SiO}_{2}$ ceramics disk (smooth surface, 60 $\mathrm{mm}$ diameter, $3 \mathrm{~mm}$ thickness, fired at $1300^{\circ} \mathrm{C}$ ). Experiments were performed in synthetic dry air $(100 \mathrm{~L} / \mathrm{h})$. The revolution symmetry of this system was particularly convenient (i) to visualize the discharges taking place all around the extremity of the point electrode, (ii) to get measurements of their propagation length (photographs) as a function of the voltage and current parameters (oscilloscope recordings of the voltage applied to the point electrode and of the discharge current measured at the grounded electrode).

\section{System II (Fig. 1)}

The study of the production of the gaseous products from a diffuse surface discharge and of their transport along an insulating surface is performed using a second electrode 
arrangement. This time, all electrodes are placed on the same side of the insulating plate. This insulating plate is an epoxy resin sample (5 mm thickness) with or without silica filler. The high voltage electrode is a stainless steel rod (1.1 mm diameter), perpendicularly directed to the insulating material surface and partially embedded (1 mm depth) in its bulk. This electrode is polarized with $50 \mathrm{~Hz}$ ac high voltages. The counter electrode consists of a linear row of 9 metallic patches embedded in the insulating material, each of them individually grounded through a $50 \Omega$ resistor R. Discharge current and applied voltage measurement techniques are the same as with system I. The high voltage electrode is located at $15 \mathrm{~mm}$ from the central grounded patch (see Fig. 1 system II). Spacing between two successive patches centres is fixed to $6 \mathrm{~mm}$, so determining vertex angles $\theta$ from 0 to $58^{\circ}$ between the central axis (from the rod basis to the central patch) and the different directions joining the rod basis to the different lateral patches. Experiments with this system were performed in ambient air ( $295 \mathrm{~K}, \sim 65 \% \mathrm{RH})$, its geometry being more suitable than the preceding one for all space resolved investigations concerning the diffuse component of the surface discharges.
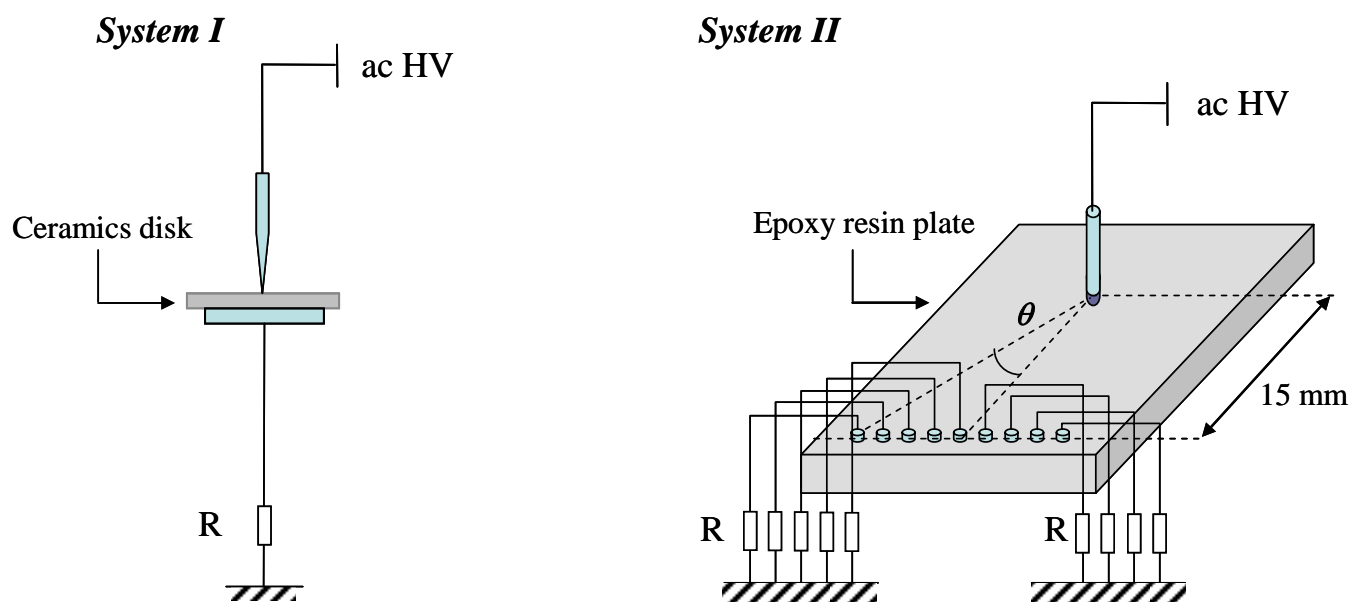

Figure 1 : Electrode systems used for the study of the discharge propagation parameters (system I) and for the analysis of the current and chemical products distributions on the dielectric surface (system II).

The investigations performed with the electrode system II are of different kinds:

- $\quad$ using the instantaneous voltage $\times$ current method, the mean power $\mathrm{P}$ is evaluated; this value, divided by the applied rms voltage gives the mean active 
discharge current; another way to measure the mean discharge current is to use a galvanometer in series with the grounded patch(es); this mean discharge current is used for comparison of the laws characterizing the diffuse component of the surface discharge with the laws governing the same component in point-to-plane air gaps (Townsend law relating the total mean current to the applied voltage, Warburg law describing the current repartition inside the discharge gap);

- $\quad$ space resolved surface energy $W_{S}$ is simply deduced from measurements of the contact angle $\alpha$ of distilled water droplets (10 $\mu$ l volume) deposited on the surface after its exposure to the discharge, using the $W_{s}=\gamma_{L V}(1+\cos \alpha)$ relation with $\gamma_{L V}=72.8 \mathrm{~mJ} . \mathrm{m}^{-2}$ for distilled water;

- $\quad$ space resolved chemical analyses are performed by capillary ion electrophoresis on the products collected in $10 \mu \mathrm{l}$ pure water droplets first deposited with a syringe on punctual sites of discharge treated surfaces and then taken off by the same way.

\section{RESULTS AND DISCUSSION}

\subsection{Propagation parameters of $1^{\text {st }}$ Toepler law discharges as a function of the current pulses amplitude (study carried out with the electrode system I)}

Figure 2 shows time integrated photographs of discharges developing on the $\mathrm{Al}_{2} \mathrm{O}_{3} / \mathrm{SiO}_{2}$ ceramics disk surface. These discharges, observed for different voltages, exhibit circular luminous areas, appearing homogeneous and characterized by their radius $r_{d}$. Figure 3 presents typical current and voltage waveforms recorded in these conditions, namely exhibiting current pulses.

Plotting $r_{d}$ values as a function of $V_{\text {peak }}$ (peak value of the applied voltage), we get a straight line in agreement with the $1^{\text {st }}$ Toepler law (Fig. 4-a). The slope of the curve gives a factor of $\sim 8 \mathrm{kV} / \mathrm{cm}$ for the propagation field of the discharge, value different from the Toepler coefficients. This may be due in particular to the use of dry synthetic air, while the gas humidity is an important parameter for the development of surface discharges, as for all gas discharges more generally [6]. 
In Figure 3, it can be seen that the current pulses occur on the voltage rise front for instantaneous onset voltages $V_{\text {onset }}(t)$ ranging from a negative value up to $V_{\text {peak }}$. Plotting $r_{d}=f\left(V_{\text {peak }}\right)$ consequently leads to overestimate the voltage onset values $V_{\text {onset }}(t)$ for which the discharges propagate; a $2 \mathrm{kV}$ shift is so observed in the linear relationship at its origin (Fig. 4-a). As a matter of fact, referring to the case represented in Fig. 3, the highest current pulse is observed for a $V_{\text {onset }}(t)$ value of $3.6 \mathrm{kV}$, i.e. 1.9 $\mathrm{kV}$ smaller than the $V_{\text {peak }}$ value $(5.5 \mathrm{kV})$.

Proportionality coefficients (propagation fields) of the first Toepler law for positive and negative applied voltage imply that the positive surface discharges expand farther than the negative ones for equivalent voltage levels. It can so be admitted that the radii $r_{d}$ of the luminous circular areas correspond to the expansion of the discharges during the positive alternations in the case of an ac high voltage signal.

It is noticeable that both number and height of the positive current pulses are fluctuating, depending on the sampled period, and that the corresponding instantaneous onset voltages $V_{\text {onset }}(t)$ are widely distributed on the voltage rise front (see voltage and current waveforms of Fig. 3). Let $I_{\max }$ be the amplitude of the highest positive current pulse (often occurring close to the $V_{\text {peak }}$ value of the applied voltage) in any high voltage period. Again a straight line is obtained (see Fig. 4-b) when plotting the radius $r_{d}$ as a function of $I_{\max }$, with a $36 \mathrm{~mA} I_{0}$ shift at its origin. This shift is attributed to the fact that $r_{d}$ is a maximum value (measured on the total exposure time $2 \mathrm{~s}$ of the photographs recording) whereas $I_{\max }$ is an average value (calculated over 3 periods of the applied voltage i.e. $180 \mu$ s).

Nevertheless, it is sufficient to assume that the limit of the luminous circular areas give significant information on the maximum expansion of the positive discharges. With the same geometry, Zhu et al. [7] demonstrated that the circular luminous area observed on the dielectric surface results from the development of number of elementary filamentary discharges during the positive half-cycle and of a uniform discharge during the negative half-cycle of the sinusoidal voltage applied to the point electrode. It can be added in the case here under investigation that, due to surface charge build up effects, the positive discharges must propagate from the point tip in an 
isotropic way on the dielectric surface, so leading to an apparently homogeneous luminous disk (Fig. 2). Taking into account the period of the high voltage signal (16.7 $\mathrm{kHz}$ ), the mean number per period of positive current pulses corresponding to the propagation of positive streamers ( 6, see Fig.3) and the exposure time of the photographs recordings (2 seconds), we can assume that each of them actually shows integrated views of about $210^{5}$ filamentary surface discharges.

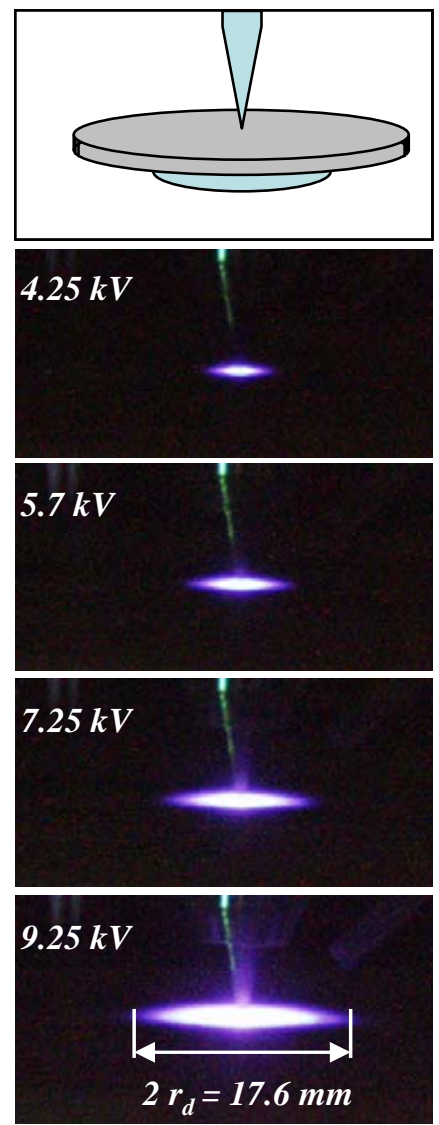

Figure 2 : Surface discharge photographs for increasing voltage $\left(\mathrm{V}_{\text {peak }}\right.$ values $)$.

Dry air, system I, 2 s exposure. 


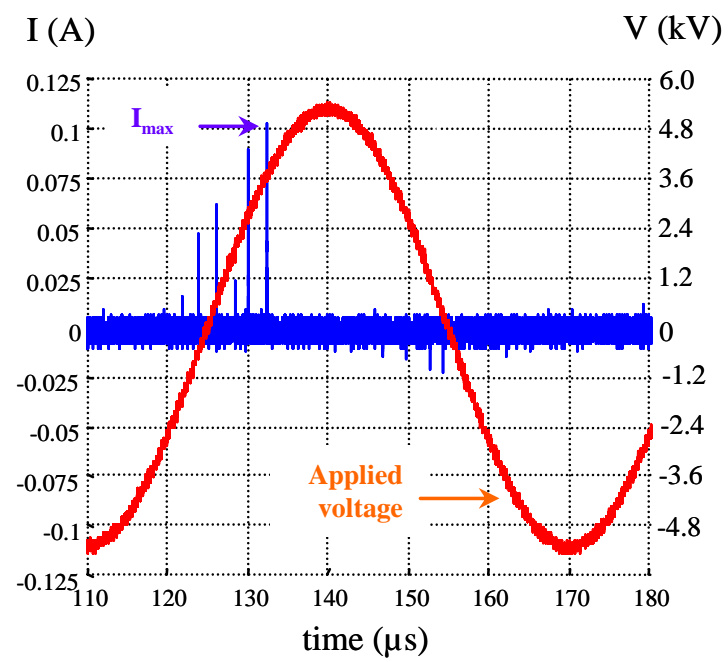

Figure 3: Typical voltage and current waveforms (system I : $\mathrm{V}_{\text {peak }}=5.5 \mathrm{kV}, 16.7 \mathrm{kHz}$ ).

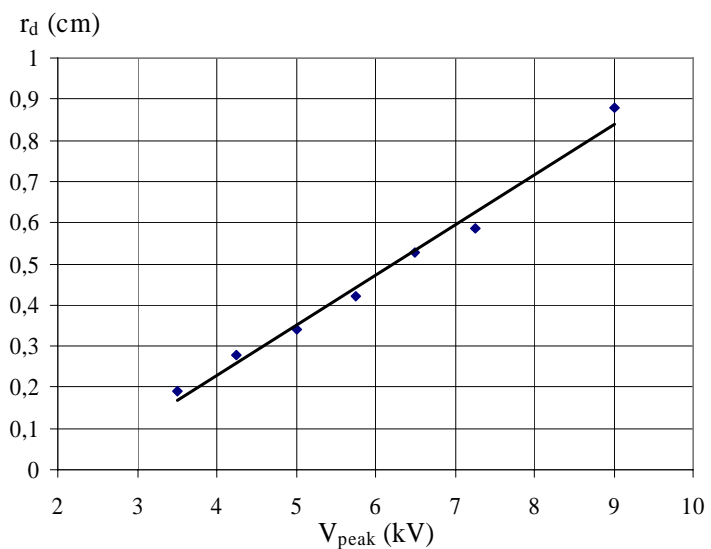

(a)

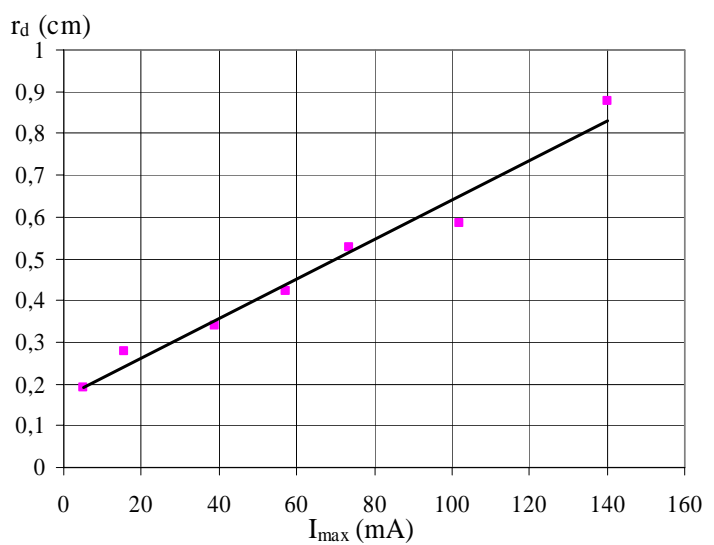

(b)

Figure 4: Radius of the luminous area formed around the tip of the point electrode as a function of $V_{\text {peak }}(\mathrm{a})$ and $I_{\max }(\mathrm{b})$. Sytem I.

To summarize this first part of the study, some relevant remarks should be made.

(i) The linearity found between the propagation radius $r_{d}$ and the applied voltage is, from a qualitative point of view, in good agreement with the literature (see in particular $[4,5,8,9]$ ) concerning discharges that obey the $1^{\text {st }}$ Toepler law;

(ii) A clear correlation is established between the Toepler figure (discharge propagation length $r_{d}$ ) and the pulsed discharge current (positive current pulses maximum amplitude $\left.I_{\max }\right)$. 
These experimental results confirm that positive filamentary discharges propagating on insulating material surfaces behave as streamers in gaseous gaps, hypothesis previously stated by Murooka et al. in a theoretical work [5].

Moreover, note the similarity presented by the propagation field of streamers in air gaps [6] on the one hand and of the $1^{\text {st }}$ Toepler law surface discharges in air on the other hand. Till now, no account has been taken here of the diffuse component of the surface discharges [10]. The next section will focus on it, using for this purpose the experimental set-up of system II.

\subsection{Space resolved current and chemical measurements (study carried out with the} electrode system II)

\section{Electrical measurements}

The mean discharge current $I$ is seen to obey the Townsend quadratic relation $I=K V\left(V-V_{s}\right)$ over a voltage interval ranging from the onset voltage $V_{s}(\sim 3 \mathrm{kV} \mathrm{rms}$ in our operating conditions) to the critical voltage value $V_{\text {crit }}(\sim 7,3 \mathrm{kV}$ rms for a new sample in our operating conditions) beyond which the discharge current $I$ more rapidly increases.

Depending on the duration of the epoxy resins exposure to the discharge, their surface properties withstand progressive changes which, in turn, influence the discharge characteristic $I(V)$. Typically, a new clean sample providing several positive current pulses per period will see these pulses progressively diminishing with time in number and correlatively increasing in size, with only one pulse per period before breakdown.

Analyzing our electrical results in terms of electrical conductance (expressed by the ratio $I / V$, see Fig. 5) showed that this conductance increases with time in a same way that with the applied voltage, i.e., to a low extent in the Townsend region (until $4.3 \mathrm{kV}$ rms $\left(V-V_{S}\right)$ value in the case of Fig. 5) and to a much larger one beyond.

But let us limit our investigations to the $V_{s}, V_{\text {crit }}$ applied voltage range obeying Townsend quadratic relation $I=K V\left(V-V_{s}\right)$. In the experiment reported in Fig. 5, $K \approx 0.385$ A. $\mathrm{V}^{-2}$ (with a 97.5\% linear regression coefficient). The current pulses 
observed indicated that filamentary discharges developed on the surface, but these filamentary discharges never exceeded a few millimetres in length, so that it can be considered that a glow-like discharge behaviour prevailed in this voltage domain. This is confirmed by the wide normalized current density profiles (Fig. 6) obtained by current measurements on the elemental patches of the low field electrode of the experimental system, in agreement, in spite of the planar configuration of the electrode system II, with the Warburg law describing the current density distribution on the plane electrode of point-to-plane air gaps [11] in glow regimes :

$$
j=j_{0} \cos ^{5} \theta
$$

with, for the electrode arrangement of system II (see Fig. 1), $\theta=\arctan (r / d), d$ being the on-axis distance between the two electrodes and $r$ the length of the grounded electrode facing the $\theta$ angle. Furthermore, comparable current density distribution profiles are obtained with two different epoxy resins (with and without $\mathrm{SiO}_{2}$ filler) so confirming a glow-like discharge behaviour in air.

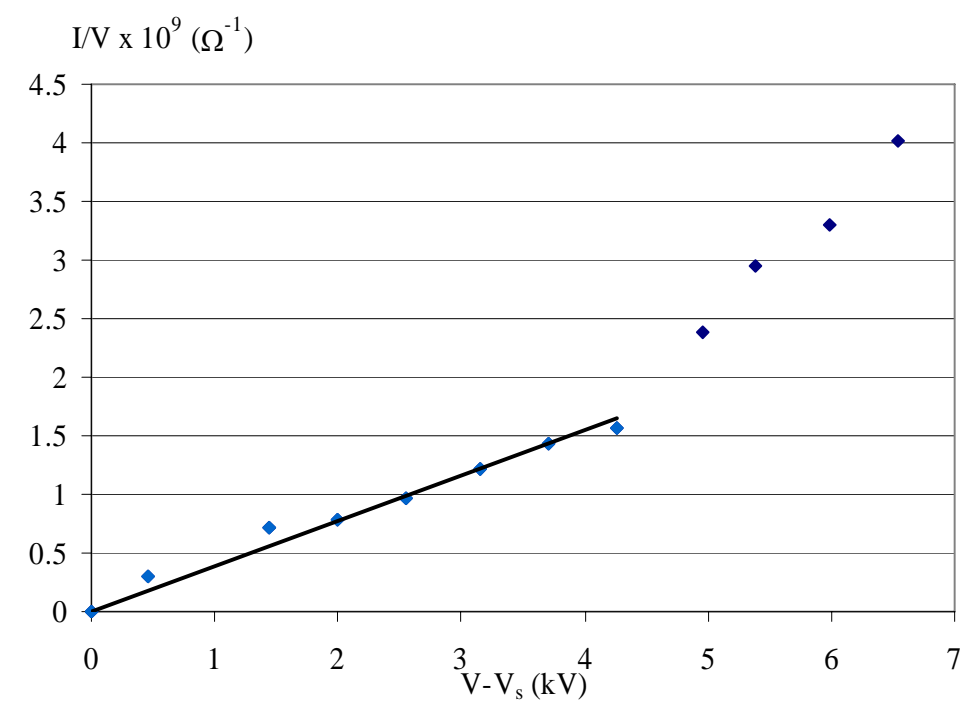

Figure 5: I(V) characteristic presented according to the Townsend relation with I/V conductance, $\mathrm{V}$ the applied voltage and $\mathrm{V}_{\mathrm{s}}$ the onset voltage (ambient air, system II, unaged epoxy resin sample). 


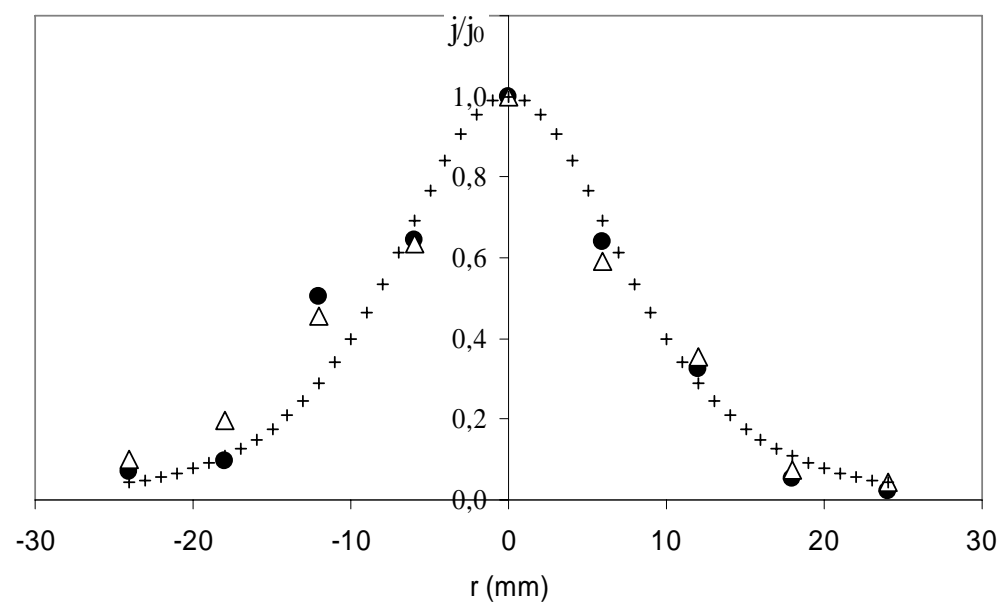

Figure 6: Current distribution profiles on the low field electrode (system II, V = $9 \mathrm{kV} \mathrm{rms).}$

Calculated Warburg profile (dotted line) and experimental data for epoxy resin with (filled points) and without (blank triangles) silica.

\section{Surface characterization}

As it was already mentioned in Section 2, surface analyses have been performed with the electrode system II by surface energy measurements on the one hand and capillary ion analysis of the surface products on the other hand. Surface energy measurements provide information on the oxidation level gained by the surface. Capillary electrophoresis informs on the nature (separation according to the apparent mobilities) and amounts (calibration for each identified product carried out in the 10$500 \mathrm{ppb}$ range) of definite surface products. In these experiments, only water dissolved negative ions were investigated. Both methods were used with space resolution.

Figure 7 shows a typical electropherogram obtained by capillary ion analysis of the discharge products and discharge/surface interaction by-products after 5 minute treatment time. Identified peaks are indicated on it. The chloride $\mathrm{Cl}^{-}$and the sulphate $\mathrm{SO}_{4}{ }^{2-}$ ions come from the ambient air pollution. The nitrates $\mathrm{NO}_{3}{ }^{-}$and nitrites $\mathrm{NO}_{2}{ }^{-}$here not observed) ions come from water dissolution of nitrogen oxides formed by air discharge reactions such as :

for $\mathrm{HNO}_{3}$ formation :

$\mathrm{OH}+\mathrm{NO}_{2}+\mathrm{M} \rightarrow \mathrm{HNO}_{3}+\mathrm{M} \quad \mathrm{k}=410^{-23} \mathrm{~T}^{-2.9} \mathrm{~cm}^{6}$ molecule ${ }^{-2} \mathrm{~s}^{-1}\left(\mathrm{M}: \mathrm{O}_{2} / \mathrm{N}_{2}\right)$ [12] 


$$
\mathrm{N}_{2} \mathrm{O}_{5}+\mathrm{H}_{2} \mathrm{O} \rightarrow 2 \mathrm{HNO}_{3} \quad \mathrm{k}=510^{-21} \mathrm{~cm}^{3} \text { molecule }{ }^{-1} \mathrm{~s}^{-1}[13]
$$

for $\mathrm{HNO}_{2}$ formation :

$$
\mathrm{OH}+\mathrm{NO}+\mathrm{M} \rightarrow \mathrm{HNO}_{2}+\mathrm{M} \quad \mathrm{k}=5.710^{-25} \mathrm{~T}^{-2.4} \mathrm{~cm}^{6} \text { molecule } \mathrm{s}^{-1}\left(\mathrm{M}: \mathrm{O}_{2} / \mathrm{N}_{2}\right) \text { [13] }
$$

The oxalate $\mathrm{C}_{2} \mathrm{O}_{4}{ }^{2-}$ ions mainly come from the polymer surface oxidation (oxidative breaking of polymer chains into low molecular weight oligomers) and a very little from atmospheric $\mathrm{CO}_{2}$ condensation induced by the gas discharge. The fumarate $\mathrm{C}_{4} \mathrm{H}_{2} \mathrm{O}_{4}{ }^{2-}$ and succinate $\mathrm{C}_{4} \mathrm{H}_{4} \mathrm{O}_{4}{ }^{2-}$ ions definitely come from the polymer surface degradation.

For what follows, the attention is limited to the two major products, nitric acid (nitrate) and oxalic acid (oxalate). Figure 8 shows two cartographies of the results obtained by discharge treatments carried out with a $8.5 \mathrm{kV}$ rms applied voltage for a 15 mm gap length between the two electrodes, but with different durations according to the method : 25 minutes treatment duration for surface by-products analysis and several hours treatment duration for surface energy evaluation. On these graphs, we have also indicated the angle delimiting Warburg's contour for the current densities at the low field electrode.

The most relevant results can be summarized as follows.

1/ Downstream (term adopted according to the hydrodynamic gas movements induced by the discharge), i.e. between the two electrodes, the area submitted to the oxidation effects appears at least as large as the area concerned with Warburg's contour; on the contrary, the areas covered by $\mathrm{NO}_{3}{ }^{-}$and $\mathrm{C}_{2} \mathrm{O}_{4}{ }^{2-}$ simultaneously are large, but not as large as the area covered by the current lines, suggesting that the electrical wind is here playing a significant role. Moreover, we see on both cartographies that the discharge also induces chemical effects upstream. Generally, the oxalates are in smaller amounts than the nitrates, especially upstream (on the cartographies, figure 8, the ratio between the concentrations of oxalates and nitrates is lower than 0.4 upstream and comprised between 0.4 and 0.7 downstream). 


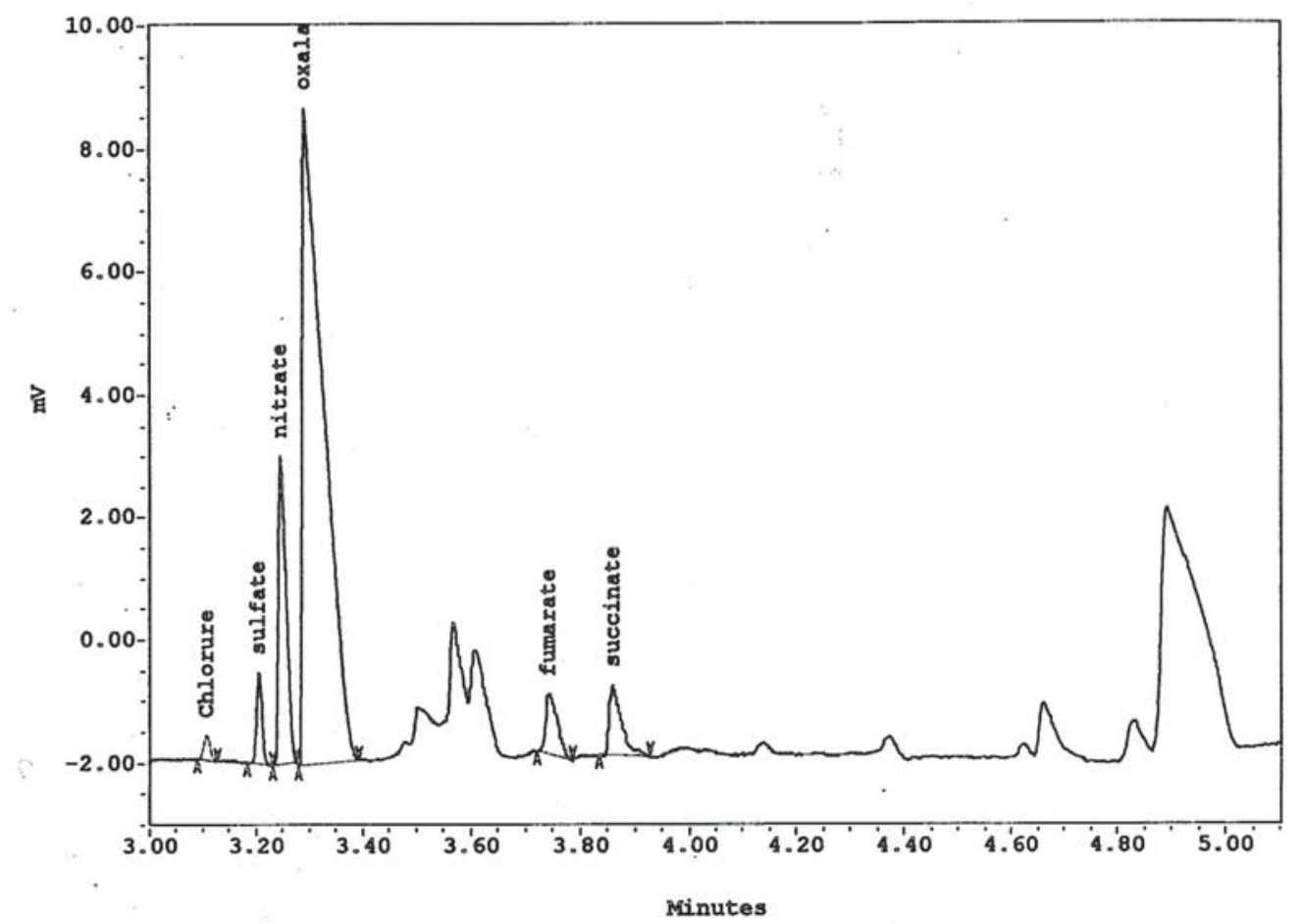

Figure 7: Typical electropherogram obtained by capillary electrophoresis for the surface products sampled close to the point electrode (5 minute treatment time at $8.5 \mathrm{kV}$ ).

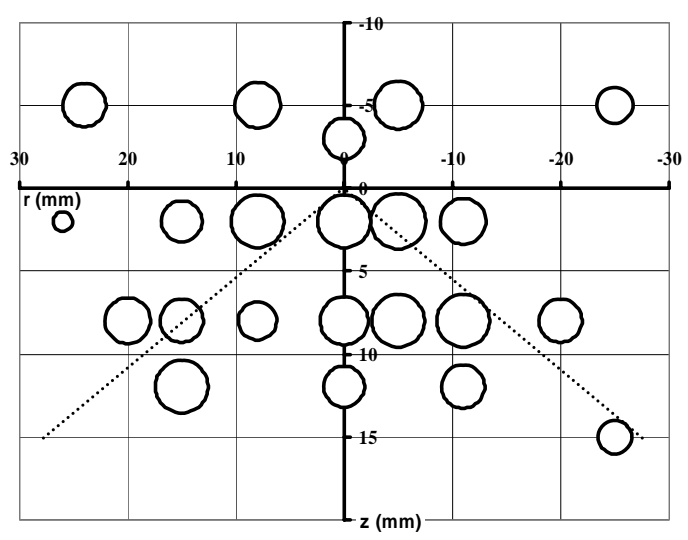

Figure 8-a: Cartography of the surface energy increase $\Delta W_{s}$ gained by epoxy resin surfaces (according to contact angle measurements of water droplets; values directly proportional to the circle areas) after several hours treatment time.

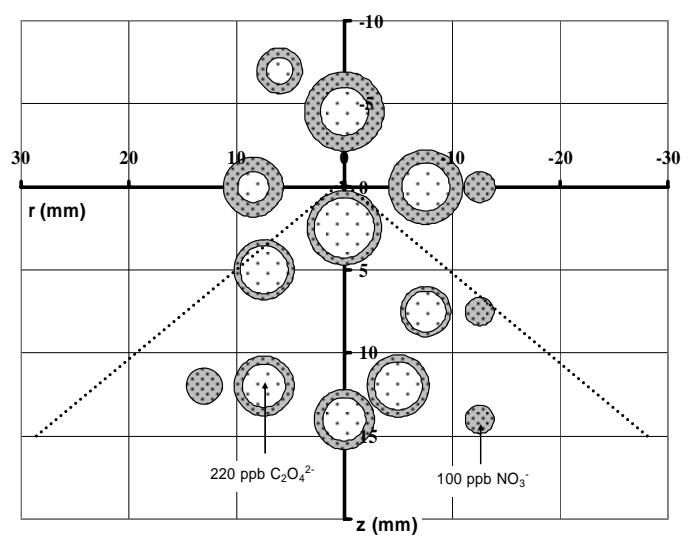

Figure 8-b: Cartography of nitrates and oxalates concentration (values directly proportional to the circle areas; external circles correspond to $\mathrm{NO}_{3}{ }^{-}$and internal to $\mathrm{C}_{2} \mathrm{O}_{4}{ }^{2-}$ ) obtained after a 25 minute treatment time.

System II, V = $8.5 \mathrm{kV}$ rms. On both cartographies, the point with coordinates $\mathrm{r}=0, \mathrm{z}=0$ marks the location of the rod electrode and the line at $\mathrm{z}=15 \mathrm{~mm}$ indicates the location of the linear row of the grounded patches. Upstream zone for $\mathrm{z}>0$. Downstream zone for $\mathrm{z}<0$. 
However, if the $\mathrm{NO}_{3}{ }^{-}$and $\mathrm{C}_{2} \mathrm{O}_{4}{ }^{2-}$ concentrations tend to increase with the treatment duration, it is not always in the same proportions and, moreover, they even exhibit opposite tendencies, in a certain range of voltages, the $\mathrm{NO}_{3}{ }^{-}$concentration showing a tendency to decrease when the voltage is increased while the $\mathrm{C}_{2} \mathrm{O}_{4}{ }^{2-}$ concentration remains more or less stable or increases.

2/ On the other hand, one can see that oxidized products and degradation products are, with different repartitions, also found upstream. This can be easily interpreted if we accept the idea that the discharge has two components:

- filamentary discharges starting their progression from the high field rod basis, in an anisotropic manner without much influence of the grounded electrode - glow discharges developing under the control of the electrical field established between the two electrodes and giving rise to the above evoked electrical wind.

3/ The $\mathrm{NO}_{3}{ }^{-}$repartition seems more concentrated around the rod electrode than the $\mathrm{C}_{2} \mathrm{O}_{4}{ }^{2-}$ repartition, itself more concentrated in the direction of the low field electrode, on the axis of the current density profile (cf. Fig. 6). This gives to think that $\mathrm{NO}_{3}{ }^{-}$should be rather produced by the filamentary discharges component located around the high field electrode and then mainly transferred towards the low field electrode by the electric wind, while $\mathrm{C}_{2} \mathrm{O}_{4}{ }^{2-}$ should rather be produced by the glow component established in the inter electrode space. The degradation products of the insulating surface lead to the formation on it of an electrolytic aqueous layer enhancing the surface conduction properties. A practical consequence of this enhancement is the formation of "dry bands" often encountered with high voltage technology.

\section{GENERAL DISCUSSION AND CONCLUSIONS}

Considering the various similarities observed between the surface discharges in air and the corona discharges in an air gap independently of their different structures (two dimensional for the first ones and three dimensional for the second ones), it can be admitted that the surface discharges are discharges not only basically of the same nature 
as the discharges in the gas, but discharges propagating in the gas above the surface. Effectively:

i. the filamentary discharges progress on the surface and in an air gap with propagation fields of the same order of magnitude;

ii. both discharges, the surface discharge and the corona discharge in the gas volume, present a glow component obeying the same rules: same Townsend quadratic relation between the discharge current and voltage, same Warburg law for the current density profiles at the low field electrode of equivalent point-towire or point-to-plane electrode systems and comparable electrical wind $[14,15]$;

iii. both discharges exhibit comparable surface effects [16].

So we can use our knowledge on the streamer propagation mechanisms in air to specifically approach the propagation mechanisms of the filamentary discharges on dielectric surfaces. The electrons at the filamentary discharge head necessary for its progression can now be supplied by photo-emission of the dielectric material, that needs photons of less energy ( $h v>4 \mathrm{eV}$ ) than the photo-ionisation of the gas $h v>12 \mathrm{eV}$ in air). Their extraction from the surface will leave a positive charge on it. This will be sufficient for the filamentary discharge channel plasma, which has its outer shells positively charged [17], to undergo a repulsive forces, keeping it away, above the surface (Fig. 8), in coherence with the first Toepler law and with the observations of Touchard's group on the electrical wind produced by the surface discharges $[14,15]$.

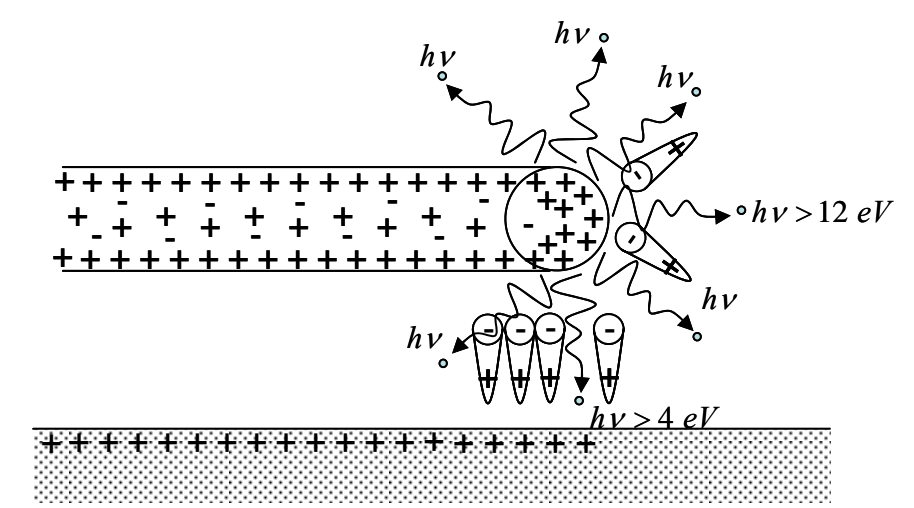

Figure 9: Schematic representation of the propagation mechanism of a filamentary discharge in the gas/surface interface.

Now comes the question: what is really limiting the $1^{\text {st }}$ Toepler law when the voltage $\mathrm{V}$ is increased? Toepler tells that the transition to his $2^{\text {nd }}$ law occurs for a critical voltage 
$V_{c r i t}$ depending on the dielectric characteristics and from a previous (unpublished) work, we know that the propagation field jumps from $\sim 5.5 \mathrm{kV} / \mathrm{cm}$ for $V<V_{\text {crit }}$ to $\sim 0.5 \mathrm{kV} / \mathrm{cm}$ beyond $V_{\text {crit }}$. This transition should be easily explained if we assume that it occurs for a critical value of the energy injected in the discharge as it is the case for the streamer-to-arc transition in an air gap [18]. The drop observed in the propagation field of the discharge at the transition should be interpreted as a consequence of a conductivity increase. As a matter of fact, beyond $V_{\text {crit }}$, the discharge channels get a clear modification of their aspect. According to Larigaldie, we have now to do with “gliding sparks” [19]. These are leader-like discharges which, by heat transfer, heat the dielectric surface. Accordingly, the material should see its surface conductivity increasing rapidly with the temperature, the surface then loosing part of its dielectric properties, at least under the discharge channels paths.

\section{REFERENCES}

[1] G. C. Lichtenberg, Novi Comment. Soc, Göttingen, 8 (1778) 168.

[2] M. Toepler, Ann.Physik, 21 (1906) 193.

[3] M.Toepler, Archiv. für Elektrotechnik, 10 (1921) 157.

[4] K. Hidaka and Y. Murooka, J. Appl. Phys., 59 (1986) 87.

[5] M. Tanaka, Y. Murooka and K. Hidaka, J. Appl. Phys., 61 (1987) 4471.

[6] C.T. Phelps, Geophys.Res.,76 (1971) 5799.

[7] Y. Zhu, T. Takada, K. Sakai, D. Tu, J. Phys. D: Appl. Phys. 29 (1996) 2892.

[8] G.J. Pietsch and V.I. Gibalov, XII ${ }^{\text {th }}$ Intern. Conf. on Gas Discharges and their Applications, Greifswald, Germany (1997) 750.

[9] V.I. Gibalov and G.J. Pietsch, J. Phys.D: Appl. Phys., 33 (2000) 2618.

[10] M. Petit, A. Goldman, M. Goldman, J. Phys. D: Appl. Phys. 35 (2002) 2969.

[11] R.S. Sigmond, J. Electrost., 18 (1986) 249.

[12] R. Atkinson, D. L. Baulch, R. A. Cox, R. F. Hampson, J. A. Kerr, J. Troe, J. Phys. Chem. Ref. Data, 18 (1989) 881.

[13] R. Peyrous, Ozone Science Engineering, 12 (1990) 41. 
[14] E. Moreau, A. Labergue and G. Touchard, Proc. $4^{\text {th }}$ Intern. Symp. on Non-Thermal Plasma Technology for Pollution Control and Sustainable Energy Development (ISNTPT-4), Panama City, USA (2004) 301.

[15] J. Pons, E. Moreau and G. Touchard, Proc. $4^{\text {th }}$ Intern. Symp. on Non-Thermal Plasma Technology for Pollution Control and Sustainable Energy Development (ISNTPT-4), Panama City, USA (2004) 307.

[16] N. Foulon-Belkacemi, M-P. Panaget, M. Goldman, A. Goldman, High Temp. Chem. Processes, 2 (1993) 399.

[17] D. Hilhorst, H.J. Hilhorst and E. Marode, Phys. Lett., 84A (1981) 424.

[18] M. Goldman and R.S. Sigmond, $15^{\text {th }}$ Intern. Conf. on Phenomena in Ionized Gases, Minsk, URSS (1981) 1148.

[19] S. Larigaldie "Etude expérimentale et modélisation de mécanismes physiques de l'étincelle glissante”, thèse de doctorat d'état, Université Paris-Sud, France, 1986. 